Review

\title{
Conventional and Future Therapies for Crohn's Disease
}

Abdulmaleek Sado ${ }^{1}$, Rahul Kalla ${ }^{2}$, Simon Campbell ${ }^{3,}{ }^{*}$

1. Department of Gastroenterology, Royal Preston Hospital, Preston, Lancashire, UK; E-Mail: sadoabdulmalik@gmail.com

2. Department of Gastroenterology, Royal Infirmary Edinburgh, Little France Crescent, Edinburgh, UK; E-Mail: kallarahul@gmail.com

3. Department of Gastroenterology, BMI Alexandra hospital, Cheadle, UK; E-Mail: simoncampbell@hotmail.com

* Correspondence: Simon Campbell; E-Mail: simoncampbell@hotmail.com

Academic Editor: Tony C. K. Tham

Special Issue: New and Old Therapeutic Options for Crohn's Disease

OBM Hepatology and Gastroenterology

2019, volume 3, issue 3

doi:10.21926/obm.hg.1903032
Received: May 20, 2019

Accepted: August 13, 2019

Published: August 14, 2019

\section{Keywords}

Crohn's disease, inflammatory bowel disease, gastroenterology, corticosteroids, immunomodulators, 5-Aminosalisylates, JAK inhibitors

\section{Introduction}

Crohn's disease (CD) is a chronic inflammatory disease mainly affecting any part of the gastrointestinal tract. It forms a part of the inflammatory bowel disease (IBD) alongside ulcerative colitis. While it is more common in the young, it can affect any age group and typically has a bimodal distribution $[1,2] . C D$ is a chronic debilitating illness which invariably influences the patients' social, economic and dietary lifestyle. Clinical presentation varies depending on the site of the disease in the gastrointestinal tract and generally includes abdominal pain, chronic diarrhea,

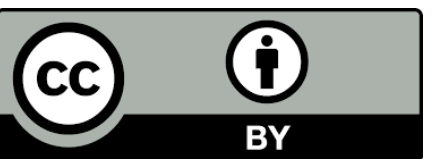

(C) 2019 by the author. This is an open access article distributed under the conditions of the Creative Commons by Attribution License, which permits unrestricted use, distribution, and reproduction in any medium or format, provided the original work is correctly cited. 
weight loss, fatigue and sometimes features of malabsorption [3, 4]. Current goals of treatment include enhancing long-lasting remission, preventing relapse, reducing the need for surgery, preventing complications and slowing disease progression. Traditionally, the clinical approach to treatment has been symptom based where patients have had to 'earn' their next treatment escalation. However, this approach has evolved rapidly in recent times. Now, treat to target strategies, more intensive monitoring with biomarkers, and use of more biological based therapies appear to give much better clinical outcomes $[5,6]$.

There is no cure currently available for $C D$, however several forms of pharmacological and nonpharmacological options of therapy have been employed over the years to induce and maintain remission, prevent relapse and improve quality of life. Since the first clinical trials by Jones and Lennard-Jones in 1966 evaluating the role of steroids in IBD treatment [2], medical research and innovation have broadened the frontiers of therapy with novel drugs now available and holding bright prospects for more effective management in future. This review aims to provide an academic discourse on the new and old treatment options for $C D$. This, we believe, will provide invaluable insight into the magnitude of progress made in efficiently managing CD.

The pathogenesis in $C D$ has been postulated to be multifactorial with genetic susceptibility, altered gut microbiota and environmental immunological priming playing key roles in $C D$ susceptibility and pathogenesis [3, 4]. Epidemiology studies have shown a sharp worldwide increase in the incidence and prevalence of $C D[7,8]$. A recent systematic review shows highest incidence in Canada (20.2 per 100,000), Australia (29.3 per 100.00) and Northern Europe (10.6 per $100,000)$. [9] Since 1990, incidence has increased in newly industrialized continents such as Africa, Asia and South America. Brazil is reported to have an annual percentage change (APC) of $+11.1 \%$ [95\% Cl 4.8-17.8] and Taiwan an APC of +4.0 [1.0-7.1]. [7] These data suggest that inflammatory bowel disease is verging on pandemic proportions.

\section{Treatment Options}

Treatment can be pharmacological, surgical or nutritional. The choice of drug therapy for Crohn's disease is influenced by several factors including efficacy, the need for induction and/or maintenance of remission, side effect profiles, long term risks and patient choice. Patients must be thoroughly assessed for any nutritional deficiencies and micronutrients must be adequately replaced before commencement of pharmacologic therapy. [8]

\subsection{Current Therapies}

\subsubsection{Corticosteroids}

Corticosteroids including prednisolone, methylprednisolone or intravenous hydrocortisone have traditionally been the cornerstone of treatment in $\mathrm{CD}$. They are mainly used for the induction of remission in active $C D$ and should not be used to maintain remission due to their short, medium and long-term side effect profile. [10] Guidelines recommend initial doses of 40mg prednisolone or $9 \mathrm{mg}$ of budesonide tapered over 8-10 weeks for disease flare. [11]

Among the traditional drugs, corticosteroids $(1 \mathrm{mg} / \mathrm{kg})$ are the most effective, with a $65-85 \%$ induction of remission, when compared to high dose sulfasalazine (3-5 g/day) (12\%) and 5aminosalicylic acid (4 g/day) (25\%). [3] A Cochrane review comparing studies looking into the role 
of corticosteroids in maintaining remission concluded that conventional systemic corticosteroids in patients with clinically quiescent CD does not appear to reduce the risk of relapse over a 24 month period of follow-up. [4] Corticosteroids are effective for induction of remission in patients with CD. [10, 12] Two randomised-control trials (RCTs) comparing corticosteroids with placebo in induction of remission in active CD found corticosteroids far more effective than placebo (RR 1.99; $95 \% \mathrm{Cl} 1.51$ to 2.64; $\mathrm{P}<0.00001)$. [12-14] In a similar way, 6 large multicentre RCTs comparing various corticosteroids vs aminosalicylates concluded that corticosteroids are more effective than 5-aminosalicylic acid (5-ASA) at inducing remission in studies with long follow-up duration ( $>15$ weeks; RR 1.65; $95 \% \mathrm{Cl} 1.33$ to 2.03; $\mathrm{P}<0.00001)$. [12] These findings support the recommendation of NICE which stipulates administering corticosteroids as first line treatment for induction of remission in acute CD flare. [10] The use of corticosteroids in maintenance of remission in CD is limited by its potential long-term complications. Well established complications of long-term use include venous thromboembolism, poor wound healing, glucose intolerance and bone loss. [15] For this reason, the American Gastroenterological Association (AGA) recommends dual X-ray absorptiometry (DEXA) scan evaluation of bone density in any patient on corticosteroids for at least 3 months or recurrent courses, any male with IBD over the age of 50 or any post-menopausal female. [16, 17] A Retrospective review of Veterans Health Administration (VHA) data from 2002-2010 found that rates of complications per 1000 person-years after IBD diagnosis were higher among corticosteroid users vs. non-corticosteroid users. [15] Infection $(54.3 \%)$, venous thromboembolism (9\%) and fragility fractures $(2.6 \%)$ were the commonly noted ones. [15]

Budesonide is a glucocorticoid and is effective in inducing remission in mild to moderate CD confined to the small bowel or proximal colon. $[8,18,19]$ It has limited systemic bioavailability due to high first pass metabolism, hence it acts locally in the gut with fewer systemic side effect profile. $[8,18]$ However, budesonide has been shown not to be effective in maintenance of remission. A Cochrane review of 6 RCTs $(n=540)$ showed that $6 \mathrm{mg}$ daily of oral budesonide had no statistically significant difference in efficacy for maintenance of remission at 3-months versus placebo (64\% vs $52 \%$, RR 1.25, 95\% $\mathrm{Cl} 1.00$ to 1.58) and even less effect at 6 and 12 months. [18]

\subsubsection{Immunomodulators}

Immunomodulators are a group of drugs which act on specific subcellular targets to alter exaggerated immune response to inflammation which plays a role in $C D$. They are generally used to maintain remission in chronic and refractory $C D[8,20]$, but should not be offered as monotherapy to induce remission. [10] Common immunomodulators used in CD include:

5-Aminosalicylates (ASAs). The ASAs are thought to act by reducing inflammation in the gastrointestinal tract. Their major role is in the maintenance of remission and prevention of relapse. However, they are more effective in inducing remission in ulcerative colitis than CD. [8, 21] They are usually used as monotherapy or in combination with budesonide or antibiotics. [22] Experience has shown some benefits of 5-ASA combination therapy in patients who exhibit poor response to single therapy, however, there is currently little evidence to support this. [22] $A$ Cochrane review comparing aminosalicylate to corticosteroids and placebo found sulfasalazine moderately beneficial over placebo but inferior to corticosteroids. [23] Olsalazine and low dose mesalazine were ineffective and not superior to placebo. However, comparison between high 
dose mesalazine (4-4.5g/day) and budesonide yielded conflicting results. [23] Evidence from The European Crohn's and Colitis Organization (ECCO) suggests some benefit in the use of sulphasalazine $3-6 \mathrm{~g} /$ day inducing remission in mild to moderate $C D$, it does not recommend the use of oral mesalazine due to insufficient evidence. [24] Generally, they should be used cautiously in selected group of patients. ECCO recommends 6-monthly Full blood count and creatinine monitoring due to significant adverse effect profile. [24] The use of Pentasa ${ }^{\circledR}$ in post-operative ileal Crohn's disease may have a role in reducing recurrence and the use of 5-ASA in Crohn's disease should generally be reserved for this group only [25].

Azathioprine. NICE recommends adding azathioprine (AZA) or 6-mercaptopurine (6-MP) to conventional corticosteroid or budesonide for induction of remission in patients with $\geq 2$ exacerbations in a 12-month period or in those in whom steroid dose cannot be tapered. [10] $A$ Cochrane review of the efficacy of AZA and 6-MP for inducing remission in active CD showed a benefit for thiopurine therapy versus placebo [OR=2.43 (95\% Cl 1.62 to 3.64), NNT=5]. [26] Thiopurine methyltransferase (TMPT) activity should be assessed before commencing azathioprine or mercaptopurine. The incidence of absent TPMT activity is approximately 1 in 300 and is a contraindication to administration of these agents while low activity necessitates dose reduction [10].

The metabolism of Azathioprine is complex and it is clear that patient response depends on their individual metabolic characteristics. The majority of absorbed AZA, a prodrug, is converted to 6-MP by a non-enzymic reaction. A small amount is converted to purine bases such as hypoxanthine which have been implicated in hypersensitivity reactions. [27] 6-MP is metabolized via three different pathways including conversion to thiouric acid by xanthine oxidase and aldehyde dehydrogenase, methylation by thiopurine-S-methyltransferase (TPMT) to form methylmercaptopurine (MeMP) and metabolism via the purine salvage pathway to form thioguanine nucleotides (TGNs). It is widely accepted that the TGNs are the primary mediators of therapeutic response. [27] The enzymes TPMT, Xanthine Oxidase and other methylating enzymes are key to both AZA resistance and toxicity (hepatotoxicity, myelosuppression). With the advent of thiopurine metabolite monitoring, the concomitant use of allopurinol now has a role in improving efficacy and reducing some side effects such as hepatotoxicity. [27] Thiopurines have a slow onset of action (up to 17 week) and induction therapies such as steroids and biologics are often needed. [8] Therefore, the decision to commence immunomodulators should be individualized bearing in mind the risk-benefit ratio vis-à-vis their disease severity and phenotype.

Methotrexate. Although randomized-controlled trials support the use of methotrexate as both induction and maintenance therapy in patients with Crohn's disease who have required at least one course on corticosteroids (ECCO e-guide), the evidence for its use in the management of CD is scant but it may have a role to play in patients who are intolerant to AZA. In addition, its high toxicity profile (see table 1 ) means its use has largely been superseded by biologic drug therapy.

Immunomodulatory drugs are also effective at maintaining remission in moderate to severe CD and in those who are steroid dependent. [8] Methotrexate is teratogenic and often poorly tolerated. Guidelines recommend its use only in patients in whom other immunomodulators/ biologics are unsuitable or as combination therapy with biological agents such as anti-TNF. [10] The Personalised Anti-TNF Therapy in Crohn's disease (PANTS) study recently found that combination of biologics with methotrexate or thiopurine reduces the risk of developing anti-TNF 
antibodies (hazard ratio 0.39 [95\% $\mathrm{Cl} 0.32-0.46]$ for infliximab; 0.44 [0.31-0.64] for adalimumab; $p<0.0001$ for both) thus mitigating nonresponse to anti-TNF therapy [28].

Table 1 Conventional and emerging drug options in CD.

\begin{tabular}{|c|c|c|c|}
\hline Drug & Indication & Contraindication & Side effect \\
\hline Corticosteroids & $\begin{array}{l}\text { Acute flare-up of } C D \\
\text { for induction } \\
\text { remission }\end{array}$ & $\begin{array}{l}\text { Hypersensitivity, systemic } \\
\text { active infection, } \\
\text { Caution: heart failure, } \\
\text { diabetes mellitus, } \\
\text { hypertension, } \\
\text { hypothyroidism, recent } \\
\text { myocardial infarction, } \\
\text { thromboembolic } \\
\text { disorders }\end{array}$ & $\begin{array}{l}\text { Poor wound healing, venous } \\
\text { thromboembolism, glucose } \\
\text { intolerance, bone loss, } \\
\text { cataract, steroid-induced } \\
\text { psychosis, cataract, weight } \\
\text { gain, gastric ulcer. }\end{array}$ \\
\hline 5-ASAs & \begin{tabular}{|l|} 
Remission of \\
induction in mild to \\
moderate CD and \\
prevention of relapse. \\
Proctosigmoiditis.
\end{tabular} & $\begin{array}{l}\text { Salicylate } \\
\text { hypersensitivity }\end{array}$ & $\begin{array}{l}\text { Insomnia, stomatitis, tinnitus, } \\
\text { seizure, vasculitis, vertigo, } \\
\text { anaema, haematuria. }\end{array}$ \\
\hline $\begin{array}{l}\text { Antibiotics } \\
\text { Metronidazole }\end{array}$ & $\begin{array}{l}\text { Mild to moderate } \\
\text { disease. Maintenance } \\
\text { of remission. }\end{array}$ & hypersensitivity & $\begin{array}{l}\text { GI upset, disulfiram-like } \\
\text { effect, metallic taste, } \\
\text { neuropathy }\end{array}$ \\
\hline $\begin{array}{l}\text { Immunomodulators } \\
\text { Azathioprine, 6- } \\
\text { mercaptopurine, } \\
\text { methotrexate }\end{array}$ & $\begin{array}{l}\text { Maintenance of } \\
\text { remission in chronic } \\
\text { and refractory } C D \text {, } \\
\text { Induction of remission } \\
\text { in conjunction with } \\
\text { steroid in patients } \\
\text { with } \geq 2 \text { exacerbation } \\
\text { in a } 12 \text {-month period. }\end{array}$ & Absent TMPT activity & $\begin{array}{l}\text { Teratogenecity and poor } \\
\text { tolerance }\end{array}$ \\
\hline Anti-TNFs & $\begin{array}{l}\text { Moderate to severe } \\
\text { CD when conventional } \\
\text { therapy fails. }\end{array}$ & $\begin{array}{l}\text { Sepsis, tuberculosis, } \\
\text { malignancy, heart failure }\end{array}$ & $\begin{array}{l}\text { Agranulocytosis, Alopecia, } \\
\text { anaemia, anxiety, arrhythmia, } \\
\text { anaphylaxis, rash, infection, } \\
\text { thrombosis, } \\
\text { thrombocytopenia }\end{array}$ \\
\hline Vedolizumab & $\begin{array}{l}\text { Induction of remission } \\
\text { of CD } \\
\text { Inadequate response } \\
\text { or intolerance to anti- } \\
\text { TNF, steroids or } \\
\text { immunomodulators } \\
\end{array}$ & Severe active infection & $\begin{array}{l}\text { Headache, nasopharyngitis, } \\
\text { nausea, arthralgia, URTI, } \\
\text { fatigue, infusion-related } \\
\text { allergic reaction. }\end{array}$ \\
\hline Ustekinumab & Promising result in & Active infection, & Arthralgia, asthenia, back \\
\hline
\end{tabular}




\begin{tabular}{|l|l|l|l|} 
& $\begin{array}{l}\text { phase } 2 \mathrm{~b} \text { trial in } \\
\text { moderate to severe } \\
\text { anti-TNF in refractory } \\
\mathrm{CD}\end{array}$ & $\begin{array}{l}\text { Pregnancy, } \\
\text { breastfeeding. }\end{array}$ & $\begin{array}{l}\text { pain, diarrhea, headache, } \\
\text { myalgia, nausea, vomiting. }\end{array}$ \\
\hline $\begin{array}{l}\text { Tofacitinib, } \\
\text { Filgotinib }\end{array}$ & $\begin{array}{l}\text { Theoretical effect on } \\
\text { induction and } \\
\text { remission of active } \\
\mathrm{CD}(\text { trial ongoing) }\end{array}$ & $\begin{array}{l}\text { Absolute lymphocyte } \\
\text { count } \\
<750 \text { cells } / \mathrm{mm}^{3,} \text { Absolute } \\
\text { neutrophil count }<1000 \\
\text { cells } / \mathrm{mm}^{3}, \text { Active } \\
\text { infection, haemoglobin } \\
<9 g / \mathrm{dL}_{\text {, pregnancy, }} \\
\text { breastfeeding. }\end{array}$ & $\begin{array}{l}\text { Anaemia, cough, leucopenia, } \\
\text { diarrhea, dyslipidaemia, } \\
\text { dyspnea, fatigue, fever, } \\
\text { gastritis, nausea, } \\
\text { musculoskeletal pain, } \\
\text { peripheral oedema, vomiting, } \\
\text { dehydration, non-melanoma } \\
\text { cancer } \\
\text { cryptococcal meningitis } \\
\text { (rare) }\end{array}$ \\
\hline
\end{tabular}

\subsubsection{Antimicrobials}

There is evidence that antimicrobials may have a role to play in the treatment of active $C D$ and indeed have been used successfully to treat complications of CD. They are thought to act by limiting the exaggerated inflammatory effect of the intestinal flora which plays some role in the pathogenesis of CD. For instance, the National Institute of Health and Care Excellence (NICE) recommends metronidazole as first line therapy in perianal disease. [10] Studies examining the effect of anti-tuberculous drugs in CD have shown conflicting results. [29] A Cochrane review concluded that anti-tuberculous therapy may provide a benefit over placebo for the prevention of relapse in participants with Crohn's disease in remission although this is limited by low quality of studies included in the systematic review. [29] Currently, both British Society of Gastroenterology (BSG) and European Crohn's and Colitis Organization (ECCO) guidelines do not support their use in the management of $C D$. The use of metronidazole in post-operative Crohn's disease for the first 3 months post-op has shown to be beneficial when combined with a treat to target approach, azathioprine and anti TNF therapy [30].

\subsubsection{Anti-TNF Therapies}

This group of agents acts locally within the gastrointestinal tract by inhibiting tumor necrosis factor, TNF, which is a potent inflammatory mediator. Anti-TNF agents are currently reserved for the treatment of patients with moderate to severe CD in whom conventional therapy has failed. [8, $10,31]$ NICE recommends Infliximab use in children over 6 years and adults while adalimumab is only recommended in adults. [10] They can be administered as single therapy or in combination with immunomodulators. [10] Most centres currently practice a 'step up' method to treatment escalation, introducing anti-TNF agents when conventional oral immunomodulatory therapies have failed. There are, however, emerging data suggesting that early use of biologics ('top down' approach) is associated with increased remission rate through 3 years of treatment. [8, 31] The CALM study, an open label randomized, controlled phase 3 study spanning 22 countries demonstrated that timely introduction of anti-TNF therapies in early CD results in improved clinical, endoscopic outcomes and disease outcomes. $[5,6]$ Studies have shown that anti-TNFs are 
effective in inducing and maintaining remission in CD. [32, 33] Infliximab $5 \mathrm{mg} / \mathrm{kg}$ or $10 \mathrm{mg} / \mathrm{kg}$, given every 8 weeks, has been shown to be effective for the maintenance of remission and maintenance of fistula healing in patients who have responded to induction therapy with infliximab (NNT=2). [32] Similarly, weekly or alternate weekly Adalimumab at a dose of 40mg has proven to be effective as maintenance in patients who respond to adalimumab induction therapy. [32] NICE recommends the use of infliximab or adalimumab in severe CD unresponsive to conventional corticosteroids and immunomodulators and suggests consideration of Infliximab in adults and children over 6 years of age [10].

Anti-TNFs are contraindicated in sepsis, tuberculosis, malignancy and heart failure. [8] Being a biological therapy, antibodies can develop against the anti-TNF agents although their role in drug loss of response is not fully understood. Drug levels and antibodies can be monitored to optimize/discontinue therapy in these individuals. [8] Side effects include anaphylaxis, rash, neutropenia and infections amongst others, hence monitoring full blood count, liver profile and renal function before every infusion is undertaken by most centres [8].

Data from 2 clinical trials, the PEGylated Antibody Fragment Evaluation in Crohn's Disease: Safety and Efficacy (PRECiSE) 1 and 2 and WELCOME trials support the use of certolizumab for induction and long-term maintenance of remission in active CD. [31] The PRECiSE2 trial showed a higher response rate in individuals on certolizumab vs placebo with $(61 \%$ [53/87] versus $33 \%$ [28/86], $\mathrm{p}<0.001)$ or without $(64 \%$ [82/128] versus 39\% [48/124], $p<0.001)$ concomitant immunomodulators at 26 weeks. [34] Certolizumab is not currently licensed for use in CD in Canada, UK and some other European countries due to insufficient evidence of efficacy (failed to reach primary end points) and the short duration of the maintenance phases as cited by the European Medicines Agency (EMA) in the PRECiSE 1 and 2 trials. [31] However it is currently approved in the United States, Switzerland and Russia for induction and maintenance in moderate to severe CD unresponsive to conventional therapy [31].

\subsubsection{Anti-Integrins}

Vedolizumab, a monoclonal antibody against $\alpha 4 \beta 7$ integrin inhibits gut lymphocyte trafficking and has been shown to be effective and safe for the treatment of Crohn's disease. [35] The United States Food and Drug Administration (FDA) currently approves vedolizumab for achieving response and remission, as well as corticosteroid-free remission. [35] In contrast to natalizumab, vedolizumab does not influence brain barrier lymphocyte trafficking, hence, it does not pose a risk for progressive multifocal leukoencephalopathy $(\mathrm{PML})$ which has been well documented with the former. Vedolizumab is administered for induction therapy as a 300-mg infusion over 30 minutes at weeks 0, 2, and 6 and then at 8-week intervals for maintenance. The European Crohn's and Colitis Organisation (ECCO) recommends discontinuation if there is no evidence of substantial therapeutic benefit by week 14 . [24, 35] The FDA, in 2014, approved vedolizumab for inducing and maintaining remission in moderate to severe ulcerative colitis (UC) and CD. Vedolizumab is indicated in those with inadequate response to- or intolerant of an anti-TNF or immunomodulator, or who have had an inadequate response to, were intolerant of, or demonstrated dependence on corticosteroids. [24, 36] Common adverse effects with relatively low frequency include headache, nasopharyngitis, nausea, arthralgia, upper respiratory tract infection and fatigue. [24] Although less common, serious infusion-related allergic reaction have been described [37]. 


\subsubsection{Ustekinumab}

Ustekinumab is a monoclonal IgG1 antibody targeting the p40 subunit of IL-12/IL-23 which is currently approved for the treatment of psoriasis and psoriatic arthritis by the FDA and the European Medicines Agency (EMA). [38, 39] In IBD, patients with moderate to severe anti-TNF refractory $C D(n=526)$ were randomised to receive placebo vs intravenous Ustekinumab $(1,3$, and $6 \mathrm{mg} / \mathrm{kg}$ ). Patients on Ustekinumab were found to have significantly higher clinical response at 6 weeks ( $23 \%$ vs $37 \%, 34 \%$ and $40 \%, p=0.02, p=0.06$, and $p=0.005)$. [39, 40] Ustekinumab is now a licensed treatment in moderate-severe $C D$, for adults who have either failed conventional therapy or anti-TNF treatment or have medical contraindications to these therapies, however, decision to start Ustekinumab should follow a discussion on its advantages and disadvantages in relation to other biological therapies [41].

\subsubsection{Others}

Ciclosporin has not been shown to be of clinical benefit in the treatment of CD. A Cochrane review of 4 RCTs revealed low dose cyclosporine $(5 \mathrm{mg} / \mathrm{kg} /$ day $)$ is not effective for the induction of remission in $C D$, studies using high dose cyclosporine are not available at present and will likely be challenging due to high risk of adverse effects [20].

\subsubsection{Nutritional}

Exclusive enteral nutrition (EEN) is used for nutritional supplementation and induction of remission in active $C D$ who have failed conventional therapy. [8, 42, 43] Studies show that corticosteroid is superior to EEN in the induction of remission in CD in adults. A Cochrane review of 10 randomized-control trials (RCTs) involving 223 participants has shown that EEN is superior to corticosteroids in induction of remission in children [83\% vs 61\%, (RR 1.35, 95\% Cl 0.92 to 1.97)]. [42] Indeed, NICE recommends the use of EEN as second-line for induction of remission in children and young people in which there is concern about growth or side effects. [10] However, administration via nasogastric (NG) tube and palatability of EEN as currently formulated may be a challenge in administration and compliance in this age group. Further high-quality studies, better administration method and improved mix of EEN constituents to enhance palatability are required. In the current era of biological therapies which have robust data on long-term outcomes, the primary use of EEN and polymeric nutrient as therapy is rarely indicated.

\subsubsection{Surgery}

Surgery is mostly indicated when medical treatment fails. $[8,10]$ NICE recommends surgery as an alternative to medical therapy in disease limited to the distal ileum in refractory disease and growth impairment despite optimal medical therapy. [10] Between $70 \%-90 \%$ of patients with CD will require surgery at some point in their lifetime. [44, 45] Common indications for surgery include intestinal obstruction, intra-abdominal or perianal abscess, enterocutaneous fistulae, and complex perianal disease. [46] The main principle is to preserve bowel length in order to avoid short bowel syndrome and intestinal failure. [8, 46] Surgery also has a role to play as first line therapy in a select group of patients with CD. Patients with discrete terminal ileal disease can be treated with lleocaecal resection as first line treatment. $[47,48]$ Stricturoplasty is recommended 
in patients with recurrent disease after small-bowel resection (in which case bowel-length preservation is of utmost importance), diffuse small-bowel involvement, or in cases with a single site of fibrotic, inactive disease $[46,49]$.

\section{New and Emerging Therapies}

A better understanding of the pathological processes involved in $C D$ has led to the development of novel therapies that are currently in several phases of trials and development which hold promise for the future of CD treatment. These agents are generally designed to target specific cellular and subcellular molecular targets which have been implicated in the pathogenesis of CD. Examples of such targets include Janus kinase (JAK), receptors for interleukin-23 (IL-23) and sphingosine-1-phosphate and tyrosine kinase receptors. $[8,50]$ The JAK/STAT (signal transducers and activators of transcription) serves as a common signaling pathway for receptors utilized by several cytokines implicated in the pathogenesis and pathophysiology of CD including IL-6, IL-5, IL9, IL-10, IL-13, IL-12/23, IL-22, granulocyte-macrophage colony-stimulating factor (GM-CSF). [51] Subunits of type 1 and 2 cytokine receptors are associated with JAK. Phosphorylation of the cytosplasmic tail of the receptor creates a docking site for STAT. The binding of STAT to JAK results in its dimerization and nuclear translocation where it stimulates transcription activation and gene expression of pro-inflammatory molecules. JAK inhibitors mitigate this cascade resulting in reduced mucosal inflammation in CD [52].

$\mathrm{IL}-12 / 23$ is produced by inflammatory cells in the gut potentiating $\mathrm{T}$ cell signaling and stimulating the production of interferon gamma and tumor necrosis factor which enhance mucosal inflammation in the gastrointestinal tract. Anti-IL-23 monoclonal antibodies (Risankizumab) have been developed and hold promise for future treatment.

$\mathrm{S} 1 \mathrm{P}$ is a membrane-derived lysophospholipid signaling molecule which regulates several cellular processes through the activation of a $\mathrm{G}$ protein coupled receptor (GPCR) family known as S1P receptors (S1PRs). $[53,54]$ There are 5 subtypes of these receptors. Type 1,4 and 5 are involved in immune system regulation. Activation of these receptors stimulates mucosal leucocyte migration implicated in CD. Targeting S1PRs has been successful in clinical trials and has led to the approval of Fingolimod, a nonselective S1PR modulator in relapsing cases of multiple sclerosis. Novel inhibitors of these receptors (ozanimod, etrasimod, amiselimod) are currently in advanced stages of clinical trials for the treatment of inflammatory bowel disease [54].

\subsection{Tofacitinib/ JAK Inhibitor}

Tofacitinib is an orally administered janus kinase (JAK) inhibitor which is important in cytokine signal transduction. [55] JAK has been implicated in several steps of the pathogenesis of inflammatory changes associated with IBD and is now a prospective target of novel drugs for the treatment of CD and ulcerative colitis. By inhibiting all members of the JAK family, tofacitinib is theoretically expected to have a clinically significant effect on induction and remission of disease. A phase $2 b$ trial comparing tofacitinib vs placebo showed improved clinical response and remission rates with 5 or $10 \mathrm{mg}$ of tofacitinib twice daily for 26 weeks but this was not statistically superior to placebo [39.5\% and $55.8 \%$ vs $38.1 \%$, respectively, p>0.05]. [55] Hence, further development of tofacitinib for $\mathrm{CD}$ has been discontinued, although a more robust study with improved sampling and higher doses may reveal promising result in the future. On the other hand, 
Filgotinib, a selective JAK1 inhibitor has shown some promise. The FITZROY trial in a 20 week phase 2 RCT ( $n=174$ ) of filgotinib vs placebo showed clinical remission at week 10 (CDAK $<150)$ in $47 \%$ of patients in the filgotinib arm vs $23 \%$ in the placebo arm [ $p=0.0077$ ] [56].

\subsection{Risankizumab}

Risankizumab is a fully human IgG2 monoclonal antibody that selectively targets the p19 subunit of IL-23 preventing its binding to the IL-23 receptor. A phase 2a study showed efficacy in moderate-severe CD in those who failed anti-TNF treatment (39\% response vs. $20.5 \%$ in placebo, $\mathrm{p}=0.01$ ). [57] The study group represented a very anti-TNF refractory population and risankizumab was able to show endoscopic remission compared to placebo $(17.1 \%$ vs. $2.6 \%$ respectively, $\mathrm{p}=0.002$ ) at week 12 . Trials in psoriasis appears to show greater efficacy with Risankizumab compared to Ustekinumab [58].

\subsection{Ozanimod}

Ozanimod is an S1PR modulator which improves mucosal inflammation in IBD by sequestrating lymphocytes in lymphoid tissues and mitigating mucosal lymphocytic migration. The TOUCHSTONE trial, a phase 2 double-blind placebo-controlled clinical trial in patients with ulcerative colitis showed clinical remission of $16 \%(p=0.048)$ and $21 \%(p=0.01)$ at weeks 8 and 32 respectively compared to placebo. [59] This has led to an attempt to replicate similar for CD. Preliminary data from the STEPTONE trial, an open-labelled phase 2 multicentre trial has shown early histological improvement in moderate to severe CD following 12 weeks of Ozanimod at $1 \mathrm{mg}$ daily with or without prior exposure to the biologics [60].

\subsection{Stem Cell Transplant}

Autologous hematopoietic stem cell transplant (AHSCT) has emerged as a promising treatment modality in refractory Crohn's disease albeit with conflicting results in available studies. A multicentre retrospective analysis of European centres involving 99 patients showed AHSCT to be relatively safe and effective in treatment-resistant CD. [61] Patients who have been treated with AHSCT have reported significant clinical improvement. On the other hand, The AHSCT for refractory Crohn's Disease (ASTIC) trial with the objective of evaluating the effect of autologous HSCT on refractory Crohn's disease compared AHSCT $(n=23)$ vs standard CD treatment $(n=22)$ and found that Eight (34.8\%) vs 2 (9.1\%) patients were free of active disease on endoscopy and radiology at final assessment (difference, $25.7 \%$ [95\% Cl, $1.1 \%$ to $47.1 \%$ ]; $P=.054$ ) with a Crohn's Disease Activity Index (CDAI) <150] at $\geq 3$ months. [62] There was however no statistically significant improvement in sustained disease remission at 1 year. This finding, alongside significant toxicity (76 serious adverse effects vs 38 in control) has limited its routine use in CD. Despite the downsides of ASTIC, it demonstrated some secondary end points of clinical significance including steroid-free clinical remission, mucosal healing, restoration of responsiveness to anti-TNF therapies to which patients were previously refractory and improved quality of life. [62] High dose of cyclophosphamide used for mobilization and conditioning in the ASTIC trial and ambitious primary endpoint set at clinical remission in 3 months have been identified as factors contributing to infectious adverse event and poor clinical outcome reported. [63] Reduced intensity AHSCT 
regimen and improved supportive care have mitigated AHSCT morbidity. [64] Hence, ASTIClite, a multicentre, parallel group randomized controlled trial was inaugurated in 2017 to compare low intensity therapy with standard therapy in terms of safety profile, efficacy and quality of life. [63] A large multicentre clinical trial sponsored by the medical research council (MRC) has also recently been initiated to establish the role of AHSCT in active CD. However, the European Commission has approved Alofisel as the first allogeneic stem cell therapy for the treatment of complex perianal fistulas in adult patients with nonactive-to-mild luminal Crohn's disease who have shown inadequate response to at least one conventional or biologic therapy [65].

\section{Future Avenues of Treatment}

With several novel therapies on the horizon and evidence of better clinical, endoscopic and disease outcomes with early therapy introduction, there is now a drive to personalise care in IBD. In order to achieve this goal clinicians must be able to stratify disease at onset, select the best drug based on the underlying disease biology with the least potential for adverse events in that individual, treat to target using biomarkers to alter the course of disease. Currently, we rely on clinical predictors (Table 2) to tailor close disease monitoring and early treatment escalation.

The first biomarker driven clinical trial has been set up in the UK that will study clinical utility of a 'top-down' vs. conventional 'step-up' treatment algorithm at diagnosis on clinical outcomes over time in CD. [66] Several other studies are now exploring novel biomarkers to help predict disease course and response to therapies in individuals with IBD. [67-69] These biomarkers will help stratify patients based on their disease biology. Beyond prognostics, drug selection will become increasingly important. Pharmacogenetic studies such as PANTS have provided us insights into anti-TNF response/non-response. We now know that HLA-DQA1*05 is associated with the development of antibodies to anti-TNF therapies. The same study group have also shown variants in the NUDT15 gene was associated with increased risk of thiopurine induced myelosuppression (OR 27.3, 95\% Cl 9.3-116.7; $p=1.1 \times 10^{-7}$ ). [70] The post- GWAS era will truly begin to help personalise care in IBD and improve outcomes.

Table 2 Clinical Predictors of an aggressive disease course.

\begin{tabular}{|l|}
\hline Clinical Predictors of aggressive course in Crohn's Disease [73] \\
\hline Requirement of steroids at diagnosis \\
\hline Age of onset (<40 years) \\
\hline Perianal disease at diagnosis \\
\hline Clinical Predictors of aggressive course in Ulcerative Colitis [74-76] \\
\hline Young age at diagnosis \\
\hline Female Gender \\
\hline Extensive colitis at presentation \\
\hline Non-smoking status \\
\hline
\end{tabular}




\section{Conclusion}

Crohn's disease is a chronic debilitating gastrointestinal disease which can have a long-lasting, debilitating effect on patients and their families. At present, no cure exists for the disease but research continues to expand the frontiers of treatment, providing more reliable options to alleviate symptoms and enhance productivity. Interestingly, the success of the human genome project in 2003 has helped to identify the over 200 genetic susceptibility loci implicated in CD which opens up the possibility of manipulating structures at molecular level to develop novel therapies targeting these genetic loci in order to influence disease progression, recurrence, susceptibility, drug response and individualized risk and outcome prediction. Personalised medicine leverages on this, with the objective of risk stratification and identifying patients' responsiveness to specific therapies. [71, 72] With the ever increasing sophistication and advancement in medical technology, personalized medicine will likely form the core of future $C D$ therapeutic models and guidelines.

We hope this review will serve as an invaluable addendum in the ever-evolving resources seeking to bring to fore the successes achieved thus far and provide information for all stakeholders to understand the challenges ahead.

Traditional Approach to Crohn's Disease care - Step up therapy

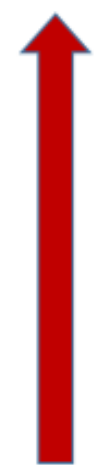

New Clinical Approach to Crohn's Disease Management

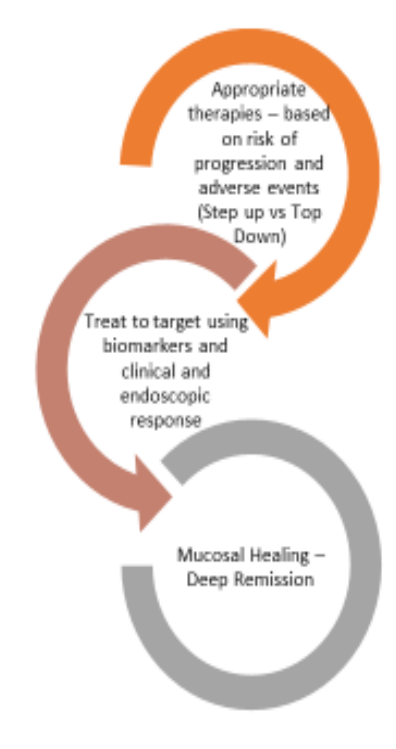

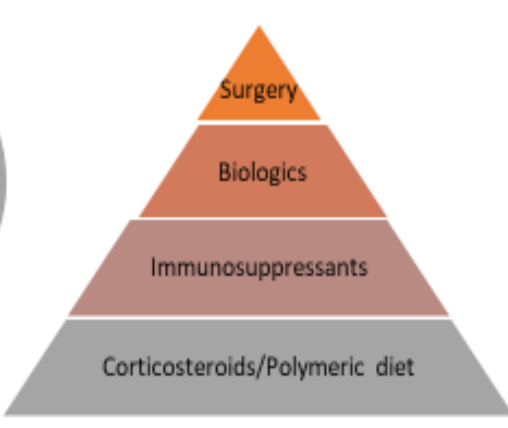

Figure 1 Traditional and New clinical approaches to Crohn's disease management.

\section{Acknowledgments}

None 


\section{Author Contributions}

1/ Abdulmaleek wrote the first draft and attended to reviewers suggestions 2/ Rahul and Simon wrote original framework for paper, proof read final article and wrote specialist sub-sections of the original draft.

\section{Funding}

None to declare.

\section{Competing Interests}

No competing interests exist.

\section{References}

1. de Mattos BRR, Garcia MPG, Nogueira JB, et al. Inflammatory bowel disease: An overview of immune mechanisms and biological treatments. Mediators Inflamm. 2015; 2015: 493012.

2. Jones JH, Lennard-Jones JE. Corticosteroids and corticotrophin in the treatment of Crohn's disease. Gut. 1966; 7: 181-187.

3. Biancone L, Pallone F. Current treatment modalities in active Crohn's disease. Ital J Gastroenterol Hepatol. 1999; 31: 508-514. http://www.ncbi.nlm.nih.gov/pubmed/10575571.

4. Steinhart AH, Ewe K, Griffiths AM, Modigliani R, Thomsen OO. Corticosteroids for maintenance of remission in Crohn's disease. Cochrane database Syst Rev. 2003; (4): CD000301. doi:10.1002/14651858.CD000301

5. Colombel J-F, Panaccione R, Bossuyt $P$, et al. Effect of tight control management on Crohn's disease (CALM): a multicentre, randomised, controlled phase 3 trial. Lancet (London, England). 2018; 390: 2779-2789. doi:10.1016/S0140-6736(17)32641-7

6. Yzet $C$, Ungaro R, Bossuyt $P$, et al. OP35 Endoscopic and deep remission at 1 year prevents disease progression in early Crohn's disease: Long-term data from CALM. J Crohn's Colitis. 2019; 13: S024-S025. doi:10.1093/ecco-jcc/jjy222.032

7. Ng SC, Shi HY, Hamidi N, et al. Worldwide incidence and prevalence of inflammatory bowel disease in the 21st century: A systematic review of population-based studies. Lancet (London, England). 2018; 390: 2769-2778. doi:10.1016/S0140-6736(17)32448-0

8. Kalla R, Ventham NT, Satsangi J, Arnott IDR. Crohn's disease. BMJ. 2014; 349: g6670. doi:10.1136/bmj.g6670

9. Molodecky NA, Soon IS, Rabi DM, et al. Increasing incidence and prevalence of the inflammatory bowel diseases with time, based on systematic review. Gastroenterology. 2012; 142: 46-54. e42; quiz e30. doi:10.1053/j.gastro.2011.10.001

10. National Institute of Health and Care Excellence. Inflammatory bowel disease: Quality standard (GID-QSD70). London Natl Inst Heal Care Excell. 2014. https://www.nice.org.uk/guidance/indevelopment/gid-qsd70/documents.

11. Mowat C, Cole A, Windsor A, et al. Guidelines for the management of inflammatory bowel disease in adults. Gut. 2011; 60: 571-607. doi:10.1136/gut.2010.224154

12. Benchimol El, Seow CH, Steinhart AH, Griffiths AM. Traditional corticosteroids for induction of remission in Crohn's disease. Cochrane database Syst Rev. 2008; (2): CD006792. 
doi:10.1002/14651858.CD006792.pub2

13. Summers RW, Switz DM, Sessions JT, et al. National Cooperative Crohn's disease Study: Results of drug treatment. Gastroenterology. 1979; 77: 847-869.

14. Malchow H, Ewe K, Brandes JW, et al. European Cooperative Crohn's Disease Study (ECCDS): Results of drug treatment. Gastroenterology. 1984; 86: 249-266.

15. Waljee AK, Wiitala WL, Govani S, et al. Corticosteroid use and complications in a US Inflammatory Bowel Disease Cohort. PLoS One. 2016; 11: e0158017.

16. Kornbluth A, Hayes M, Feldman S, et al. Do guidelines matter? Implementation of the ACG and AGA osteoporosis screening guidelines in inflammatory bowel disease (IBD) patients who meet the guidelines' criteria. Am J Gastroenterol. 2006; 101: 1546-1550. doi:10.1111/j.15720241.2006.00571.x

17. Bernstein CN, Leslie WD, Leboff MS. AGA technical review on osteoporosis in gastrointestinal diseases. Gastroenterology. 2003; 124: 795-841. doi:10.1053/gast.2003.50106

18. Kuenzig ME, Rezaie A, Seow CH, et al. Budesonide for maintenance of remission in Crohn's disease. Cochrane database Syst Rev. 2014; (8): CD002913.

19. Benchimol El, Seow CH, Otley AR, Steinhart AH. Budesonide for maintenance of remission in Crohn's disease. Cochrane database Syst Rev. 2009; (1): CD002913.

20. McDonald JWD, Feagan BG, Jewell D, Brynskov J, Stange EF, Macdonald JK. Cyclosporine for induction of remission in Crohn's disease. Cochrane database Syst Rev. 2005; (2): CD000297. doi:10.1002/14651858.CD000297.pub2

21. Carter MJ, Lobo AJ, Travis SPL, IBD Section BS of G. Guidelines for the management of inflammatory bowel disease in adults. Gut. 2004; 53: V1-16. doi:10.1136/gut.2004.043372

22. Bayless T. The role of aminosalicylates in Crohn's Disease. Gastroenterol Hepatol (N Y). 2006; 2: 159-160. http://www.ncbi.nlm.nih.gov/pubmed/5335634.

23. Lim W-C, Wang Y, MacDonald JK, Hanauer S. Aminosalicylates for induction of remission or response in Crohn's disease. Cochrane database Syst Rev. 2016; 7: CD008870. doi:10.1002/14651858.CD008870.pub2

24. Gomollón F, Dignass A, Annese V, et al. 3rd European evidence-based consensus on the diagnosis and management of Crohn's Disease 2016: Part 1: Diagnosis and medical management. J Crohns Colitis. 2017; 11: 3-25. doi:10.1093/ecco-jcc/jjw168

25. Rampton DS. Antagonist: Crohn's disease recurrence can be prevented after ileal resection. Gut. 2002; 51: 153-154. http://www.ncbi.nlm.nih.gov/pubmed/12117871.

26. Prefontaine E, Sutherland LR, Macdonald JK, Cepoiu M. Azathioprine or 6-mercaptopurine for maintenance of remission in Crohn's disease. Cochrane database Syst Rev. 2009; (1): CD000067. doi:10.1002/14651858.CD000067.pub2

27. Goel RM, Blaker P, Mentzer A, Fong SCM, Marinaki AM, Sanderson JD. Optimizing the use of thiopurines in inflammatory bowel disease. Ther Adv Chronic Dis. 2015; 6: 138-146. doi:10.1177/2040622315579063

28. Kennedy NA, Heap GA, Green HD, et al. Predictors of anti-TNF treatment failure in anti-TNFnaive patients with active luminal Crohn's disease: A prospective, multicentre, cohort study. lancet Gastroenterol Hepatol. 2019; 4: 341-353. doi:10.1016/S2468-1253(19)30012-3

29. Patton PH, Parker CE, MacDonald JK, Chande N. Anti-tuberculous therapy for maintenance of remission in Crohn's disease. Cochrane database Syst Rev. 2016; 7: CD000299. doi:10.1002/14651858.CD000299.pub3 
30. De Cruz $P$, Kamm MA, Hamilton AL, et al. Crohn's disease management after intestinal resection: A randomised trial. Lancet. 2015; 385: 1406-1417. doi:10.1016/S01406736(14)61908-5

31. Schreiber S. Certolizumab pegol for the treatment of Crohn's disease. Therap Adv Gastroenterol. 2011; 4: 375-389. doi:10.1177/1756283X11413315

32. Behm BW, Bickston SJ. Tumor necrosis factor-alpha antibody for maintenance of remission in Crohn's disease. Cochrane database Syst Rev. 2008; (1): CD006893.

33. Akobeng AK, Zachos $M$. Tumor necrosis factor-alpha antibody for induction of remission in Crohn's disease. Cochrane database Syst Rev. 2004; (1): CD003574.

34. Schreiber S, Khaliq-Kareemi M, Lawrance IC, et al. S1037 Certolizumab pegol demonstrates efficacy in maintaining response and remission in patients with active Crohn's disease regardless of their immunosuppressant treatment status at entry to the PRECiSE 2 study. Gastroenterology. 2010; 138: S-165. doi:10.1016/S0016-5085(10)60755-X

35. Ha C, Kornbluth A. Vedolizumab as a treatment for Crohn's disease and ulcerative colitis. Gastroenterol Hepatol (N Y). 2014; 10: 793-800.

36. Verbeeck J, Van Assche G, Ryding J, et al. JC viral loads in patients with Crohn's disease treated with immunosuppression: Can we screen for elevated risk of progressive multifocal leukoencephalopathy? Gut. 2008; 57: 1393-1397. doi:10.1136/gut.2007.145698

37. Colombel J-F, Sands BE, Rutgeerts $P$, et al. The safety of vedolizumab for ulcerative colitis and Crohn's disease. Gut. 2017; 66: 839-851. doi:10.1136/gutjnl-2015-311079

38. Leonardi CL, Kimball AB, Papp KA, et al. Efficacy and safety of ustekinumab, a human interleukin-12/23 monoclonal antibody, in patients with psoriasis: 76-week results from a randomised, double-blind, placebo-controlled trial (PHOENIX 1). Lancet (London, England). 2008; 371: 1665-1674. doi:10.1016/S0140-6736(08)60725-4

39. Amiot A, Peyrin-Biroulet L. Current, new and future biological agents on the horizon for the treatment of inflammatory bowel diseases. Therap Adv Gastroenterol. 2015; 8: 66-82. doi:10.1177/1756283X14558193

40. Sandborn WJ, Gasink C, Gao L-L, et al. Ustekinumab induction and maintenance therapy in refractory Crohn's disease. N Engl J Med. 2012; 367: 1519-1528. doi:10.1056/NEJMoa1203572

41. National Institute of Health and Care Excellence. Ustekinumab for moderately to severely active Crohn's disease after previous treatment. 2017. https://www.nice.org.uk/guidance/ta456/chapter/1-Recommendations.

42. Narula N, Dhillon A, Zhang D, Sherlock ME, Tondeur M, Zachos M. Enteral nutritional therapy for induction of remission in Crohn's disease. Cochrane database Syst Rev. 2018; 4: CD000542. doi:10.1002/14651858.CD000542.pub3

43. Zachos $M$, Tondeur M, Griffiths AM. Enteral nutritional therapy for induction of remission in Crohn's disease. Cochrane database Syst Rev. 2007; (1): CD000542. doi:10.1002/14651858.CD000542.pub2

44. Canin-Endres J, Salky B, Gattorno F, Edye M. Laparoscopically assisted intestinal resection in 88 patients with Crohn's disease. Surg Endosc. 1999; 13: 595-599.

45. Mekhjian HS, Switz DM, Watts HD, Deren JJ, Katon RM, Beman FM. National Cooperative Crohn's Disease Study: factors determining recurrence of Crohn's disease after surgery. Gastroenterology. 1979; 77: 907-913. http://www.ncbi.nlm.nih.gov/pubmed/467942.

46. Lewis RT, Maron DJ. Efficacy and complications of surgery for Crohn's disease. Gastroenterol 
Hepatol (N Y). 2010; 6: 587-596. http://www.ncbi.nlm.nih.gov/pubmed/21088749.

47. Nordgren SR, Fasth SB, Oresland TO, Hultén LA. Long-term follow-up in Crohn's disease. Mortality, morbidity, and functional status. Scand J Gastroenterol. 1994; 29: 1122-1128. http://www.ncbi.nlm.nih.gov/pubmed/7886401.

48. Tilney HS, Constantinides VA, Heriot AG, et al. Comparison of laparoscopic and open ileocecal resection for Crohn's disease: A metaanalysis. Surg Endosc. 2006; 20: 1036-1044. doi:10.1007/s00464-005-0500-3

49. Katariya RN, Sood S, Rao PG, Rao PL. Stricture-plasty for tubercular strictures of the gastrointestinal tract. Br J Surg. 1977; 64: 496-498. http://www.ncbi.nlm.nih.gov/pubmed/922310.

50. Panés J, Sandborn WJ, Schreiber S, et al. Tofacitinib for induction and maintenance therapy of Crohn's disease: Results of two phase Ilb randomised placebo-controlled trials. Gut. 2017; 66: 1049-1059. doi:10.1136/gutjnl-2016-312735

51. Zhou L, Ivanov II, Spolski R, et al. IL-6 programs T(H)-17 cell differentiation by promoting sequential engagement of the IL-21 and IL-23 pathways. Nat Immunol. 2007; 8: 967-974. doi:10.1038/ni1488

52. Pérez-Jeldres T, Tyler CJ, Boyer JD, et al. Targeting cytokine signaling and lymphocyte traffic via small molecules in Inflammatory Bowel Disease: JAK inhibitors and S1PR agonists. Front Pharmacol. 2019; 10: 212. doi:10.3389/fphar.2019.00212

53. Peyrin-Biroulet L, Christopher R, Behan D, Lassen C. Modulation of sphingosine-1-phosphate in inflammatory bowel disease. Autoimmun Rev. 2017; 16: 495-503.

54. Danese S, Furfaro F, Vetrano S. Targeting S1P in Inflammatory Bowel Disease: New avenues for modulating intestinal leukocyte migration. J Crohns Colitis. 2018; 12: S678-S686. doi:10.1093/ecco-jcc/jjx107

55. De Vries LCS, Wildenberg ME, De Jonge WJ, D'Haens GR. The future of janus kinase inhibitors in Inflammatory Bowel Disease. J Crohns Colitis. 2017; 11: 885-893. doi:10.1093/eccojcc/jjx003

56. Vermeire $S$, Schreiber $S$, Petryka $R$, et al. Clinical remission in patients with moderate-tosevere Crohn's disease treated with filgotinib (the FITZROY study): Results from a phase 2, double-blind, randomised, placebo-controlled trial. Lancet (London, England). 2017; 389: 266275. doi:10.1016/S0140-6736(16)32537-5

57. Feagan BG, Sandborn WJ, D'Haens G, et al. Induction therapy with the selective interleukin-23 inhibitor risankizumab in patients with moderate-to-severe Crohn's disease: A randomised, double-blind, placebo-controlled phase 2 study. Lancet (London, England). 2017; 389: 16991709. doi:10.1016/S0140-6736(17)30570-6

58. Papp KA, Blauvelt A, Bukhalo $M$, et al. Risankizumab versus Ustekinumab for moderate-tosevere plaque psoriasis. N Engl J Med. 2017; 376: 1551-1560. doi:10.1056/NEJMoa1607017

59. Sandborn WJ, Feagan BG, Wolf DC, et al. Ozanimod induction and maintenance treatment for ulcerative colitis. N Engl J Med. 2016; 374: 1754-1762. doi:10.1056/NEJMoa1513248

60. B. G. Feagan, G. D'Haens, K. Usiskin, J. Liu, D. Paul RKP. P661 Early histological improvement demonstrated with oral ozanimod in patients with moderately to severely active Crohn's disease in the STEPSTONE trial. Eur Crohns Colitis Organ Inflamm Bowel Dis. 2019. https://www.ecco-ibd.eu/publications/congress-abstract-s/abstracts-2019/item/p661-earlyhistological-improvement-demonstrated-with-oral-ozanimod-in-patients-with-moderately-toseverely-active-crohn-8217-s-disease-in-the-stepstone-trial.html\%0D. 
61. Brierley CK, Castilla-Llorente C, Labopin M, et al. Autologous Haematopoietic stem cell transplantation for Crohn's disease: A retrospective survey of long-term outcomes from the european society for blood and marrow transplantation. J Crohns Colitis. 2018. doi:10.1093/ecco-jcc/jjy069

62. Hawkey CJ, Allez M, Clark MM, et al. Autologous hematopoetic stem cell transplantation for refractory Crohn disease: A randomized clinical trial. JAMA. 2015; 314: 2524-2534. doi:10.1001/jama.2015.16700

63. Snowden JA, Hawkey C, Hind D, et al. Autologous stem cell transplantation in refractory Crohn's disease - low intensity therapy evaluation (ASTIClite): Study protocols for a multicentre, randomised controlled trial and observational follow up study. BMC Gastroenterol. 2019; 19: 82. doi:10.1186/s12876-019-0992-2

64. Jauregui-Amezaga A, Rovira M, Marín P, et al. Improving safety of autologous haematopoietic stem cell transplantation in patients with Crohn's disease. Gut. 2016; 65: 1456-1462. doi:10.1136/gutjnl-2015-309836

65. Panes J. Stem cell therapy approved in Europe to treat fistulizing Crohn's disease. Heal Gastroenterol. 2018. https://www.healio.com/gastroenterology/inflammatory-boweldisease/news/online/\%7B3d74e894-207e-41d0-8437-058d37f302c4\%7D/stem-cell-therapyapproved-in-europe-to-treat-fistulizing-crohns-disease\%0D.

66. Parkes $M$, Noor NM, Dowling $F$, et al. Predicting outcomes For Crohn's dlsease using a moLecular biomarkEr (PROFILE): Protocol for a multicentre, randomised, biomarker-stratified trial. BMJ Open. 2018; 8: e026767. doi:10.1136/bmjopen-2018-026767

67. Kalla R, Kennedy NA, Ventham NT, et al. Serum calprotectin: A novel diagnostic and prognostic marker in Inflammatory Bowel Diseases. Am J Gastroenterol. 2016; 111: 1796-1805. doi:10.1038/ajg.2016.342

68. West NR, Hegazy AN, Owens BMJ, et al. Oncostatin M drives intestinal inflammation and predicts response to tumor necrosis factor-neutralizing therapy in patients with inflammatory bowel disease. Nat Med. 2017; 23: 579-589. doi:10.1038/nm.4307

69. Kalla R, Adams A, Nimmo E, et al. Epigenetic alterations in inflammatory bowel disease: The complex interplay between genome-wide methylation alterations, germline variation, and gene expression. Lancet. 2017; 389: S52. doi:10.1016/S0140-6736(17)30448-8

70. Walker GJ, Harrison JW, Heap GA, et al. Association of genetic variants in NUDT15 with thiopurine-induced myelosuppression in patients with Inflammatory Bowel Disease. JAMA. 2019; 321: 773-785. doi:10.1001/jama.2019.0709

71. Flamant M, Roblin X. Inflammatory bowel disease: Towards a personalized medicine. Therap Adv Gastroenterol. 2018; 11: 1756283X17745029. doi:10.1177/1756283X17745029

72. Boyapati RK, Kalla R, Satsangi J, Ho G-T. Biomarkers in search of precision medicine in IBD. Am J Gastroenterol. 2016; 111: 1682-1690. doi:10.1038/ajg.2016.441

73. Beaugerie L, Seksik P, Nion-Larmurier I, Gendre JP, Cosnes J. Predictors of Crohn's disease. Gastroenterology. 2006; 130: 650-656. doi:10.1053/j.gastro.2005.12.019

74. Höie O, Wolters F, Riis L, et al. Ulcerative colitis: patient characteristics may predict 10-yr disease recurrence in a European-wide population-based cohort. Am J Gastroenterol. 2007; 102: 1692-1701. doi:10.1111/j.1572-0241.2007.01265.x

75. Langholz E, Munkholm P, Davidsen M, Binder V. Course of ulcerative colitis: Analysis of changes in disease activity over years. Gastroenterology. 1994; 107: 3-11. 
http://www.ncbi.nlm.nih.gov/pubmed/8020674.

76. Henriksen M, Jahnsen J, Lygren I, Vatn MH, Moum B, IBSEN Study Group. Are there any differences in phenotype or disease course between familial and sporadic cases of inflammatory bowel disease? Results of a population-based follow-up study. Am J Gastroenterol. 2007; 102: 1955-1963. doi:10.1111/j.1572-0241.2007.01368.x

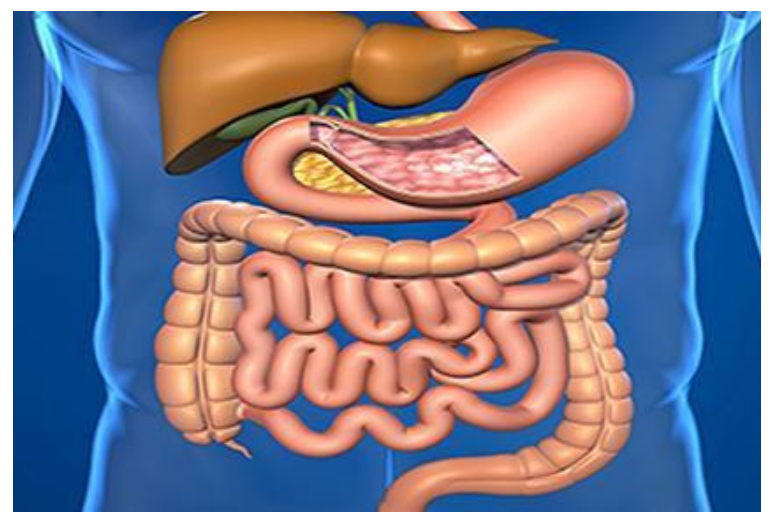

Enjoy OBM Hepatology and Gastroenterology by:

1. Submitting a manuscript

2. Joining in volunteer reviewer bank

3. Joining Editorial Board

4. Guest editing a special issue

For more details, please visit: http://www.lidsen.com/journals/hg 